\title{
Treatment and Intervention for Children with Developmental Disabilities
}

\author{
Junko Teruyama
}

\begin{abstract}
Autism has come to be broadly acknowledged in Japan over the past decade through the spread of the term hattatsu shoggai. Translated literally as "developmental disability," it is a generic term for congenital disabilities caused by brain disorders. The three major categories of disability that hattatsu shogai encompasses are learning disabilities (LD), attention deficit hyperactivity disorder (ADHD), and autism spectrum disorder (ASD). The term for developmental disabilities is not a diagnostic category in itself. Rather, it is a term in general usage-used by both laypeople and psychiatrists - to refer to any of these disabilities, alone or in combination (see figure 12).

In recent years, educational and welfare policies for children with developmental disabilities in Japan have emphasized the importance of early diagnosis and intervention. The mandatory physical checkup for three year olds has provided one of the primary opportunities for screening, as has the pre-enrollment checkup for elementary school enrollment. Many children who receive diagnoses early on through these screening processes are referred to remedial education programs (ryōiku) for the purpose of scaffolding their development and learning, and helping them better adapt to preschool or elementary school regimens. Remedial education programs vary greatly. Since there is no institutionalized system to accredit or license these programs, it is solely up to the parent to choose among a vast range of programs administered by different organizations and based on diverse methods of instruction. Some intervention programs are run by children's hospitals or clinics, while others are run by nonprofit organizations, private corporations, or parents' organizations. Some meet weekly, while others enforce a more intensive commitment or involve overnight stays; still others are based on distance learning.
\end{abstract}




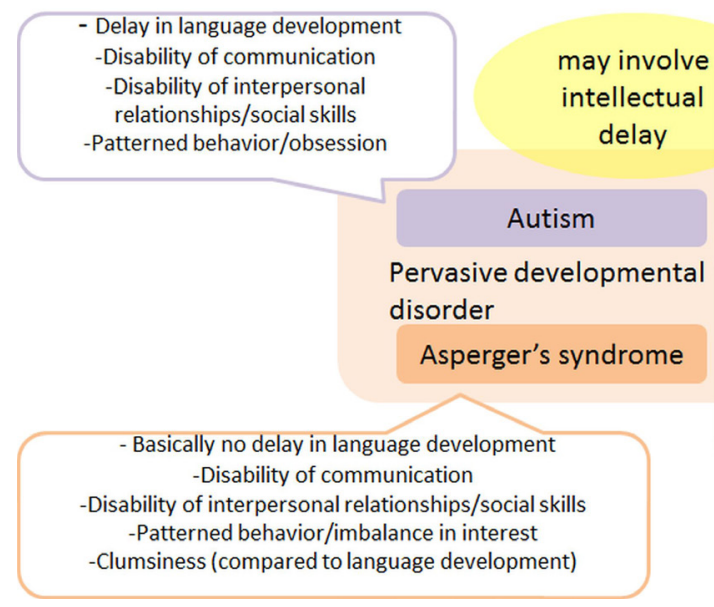

FIGURE 12. Conceptual diagram of developmental disabilities. Courtesy of the author.

Their approaches are similarly diverse, but the most common program consists of social activities and individualized learning exercises, implemented in ways that are informed by practices in applied behavior analysis (ABA), social skill training, TEACCH (Treatment and Education of Autistic and Related Communication Handicapped Children), and play therapy, among other clinical methods of intervention. Some parents elect to try other, less conventional methods such as art therapy or animal therapy, and some program administrators are venturing to collaborate with emerging approaches such as the applied use of robots to assist in social interaction. Apart from the vast array of remedial education programs that are available today, one can find numerous books on how to practice remedial education at home, and there also are many seminars and symposiums for professionals to share and exchange thoughts on successful methods of intervention.

The term ryōiku (remedial education) is short for chiryō-kyōiku (treatment education) and was originally introduced as the Japanese translation of the German term Heilpädagogik. For more than four decades, the term has been used to refer to remedial education programs for children with various disabilities, including physical as well as cognitive disabilities. Early scholars defined ryōiku as "a special educational scheme that incorporates findings in medicine, psychology, education, sociology, and engineering, among others, to help with the self-fulfillment of children who will not fully benefit from regular education and instruction" (Itō 1970), and as "education with the purpose of medical treatment, education that includes treatment, or a method of treatment utilizing educational means" (Kan 1969). As implied by these early definitions, the relationship between chiryō (medical treatment) and kyōiku (education), in the context of ryoiku practice, has been, and 
continues to be, interpreted in multiple and divergent ways. Today, psychiatrists rarely conduct remedial education programs for children with developmental disabilities and, in that sense, the "medical treatment" dimension to remedial education is on the wane. There exists, instead, an increasingly ambivalent sentiment towards the notion of corrective intervention. The "education" dimension, on the other hand, is incorporated in remedial education practices only in a generalized sense, in that most remedial education programs include very little academic curricula and focus more on the child's behavioral and social training and growth (for more on the emphasis placed on social training for young children, see chapter 12).

This chapter is primarily based on my ethnographic fieldwork at several remedial education programs from 2008 to 2010. A significant part of this fieldwork took place at a privately-owned program in a metropolitan setting where I worked as an intern. The program attracted thirty to forty children aged three to fifteen, each of whom belonged to a particular class grouped by age and ability that mostly met once a week. There were two full-time staff members who were responsible for the overall management, and several interns and volunteers who came on a part-time basis to support the day-to-day programs. Apart from this specific program, I also visited several other programs to conduct participant observation and interviews with staff members and parents.

The common purpose of all remedial education programs, despite their diverse methods, is to help children "fit in" at school and in the larger society. The question of what it means to "fit in" entails larger questions regarding individuality and membership in Japanese society. In other words, external factors that define the type and degree of individual "difference" that can be subsumed into the mainstream population inform the designs and practices of intervention programs. Children with developmental disabilities are considered to be incapable of adapting to the regular classroom without the extra support provided by these programs. By looking closely at how these programs function and how they engage with the ideas of caring for children with developmental disabilities and curing the disabilities, I aim to shed light on the meanings of difference and adaptation, as expressed in practice in the remedial education setting. In other words, I posit that children in this setting act as symbolic agents taking on two conflicting roles; that of the defiant and resistant rebel/delinquent who requires appropriate socialization and training, and that of the vulnerable and susceptible member of society who requires protection, support, and encouragement. I will show how those who work in the remedial education programs interact with the children, interpret their behavior and aim to elicit positive changes while working with these conflicting images of the child. I focus primarily on the environment and the interaction that takes place in this setting, but my observations and interpretations are also informed by semi-structured interviews with parents, staff members, and older children (where possible) that I conducted at a later date. 


\section{SPATIAL DISPOSITION AND STRUCTURE}

On the first day of my visit to one remedial education program, a staff member welcomed me and told me to wait in the playroom until the day's program started. Several staff members were standing in the room, chatting about the activities that were to take place that day. I sat by myself in a corner of the room, by a wall filled with boxes that contained toys. The room was about seven hundred square feet, the size of an elementary school classroom, and was divided into sections by the placement of low cabinets (see figure 13).

The section that I was in was carpeted so that children could play on the floor. Another section was organized as a workshop with large tables and arts and crafts equipment. The largest section looked like a classroom, with wooden floors and several small chairs and a blackboard mounted on the wall. About fifteen minutes before the program, parents began dropping off their preschool-aged children. The children were allowed to play freely with the toys until the program began. Knowing this, they walked right into my section and started opening the boxes to look for their favorite toys. One of the boys took out a train and started dragging it across the floor. When the train bumped into my foot, the boy looked up and glanced at me without interest. A staff member who was standing nearby spoke loudly in a cheerful tone: "Wow, you're the first one to notice her! She's Junko-sensei." The boy didn't respond, but as he continued to drag the train on the floor, he avoided me.

Seeing that everyone had arrived, the staff members brought the children to the main section and sat the children in small chairs organized in a circle. There were six children, all of them in preschool, and only one of them was a girl. One of the staff members took attendance. When their names were called, children responded by saying "hai" (here). Some yelled and jumped up excitedly from their chairs. The girl had turned her chair sideways and sat as if turning her back to the center of the circle. When it was her turn, a staff member walked up to her and held out her hand while calling the girl's name. The girl temporarily turned around and slapped that hand in response. Another staff member standing nearby whispered to me: "That girl has selective muteness. She doesn't speak here. Her mother says she talks just fine at home, though."

After attendance was taken, a staff member placed colored magnetic stickers with illustrations of activities on the board, explaining what activities would take place that day and the order in which they were to be done, thus giving the children a general overview of the day's schedule. Visualization of the day's agenda at the beginning of the day was a crucial part of all the remedial education programs that I observed. It was explained to me that children needed to have a grasp of the larger picture of how the day was going to be organized. Throughout the day, the staff members would continue to remind children of where they were in the schedule, when the current activity was going to finish ("Look at the clock. When the long arm hits eight, you have to come back here"), and what would be coming up next. 


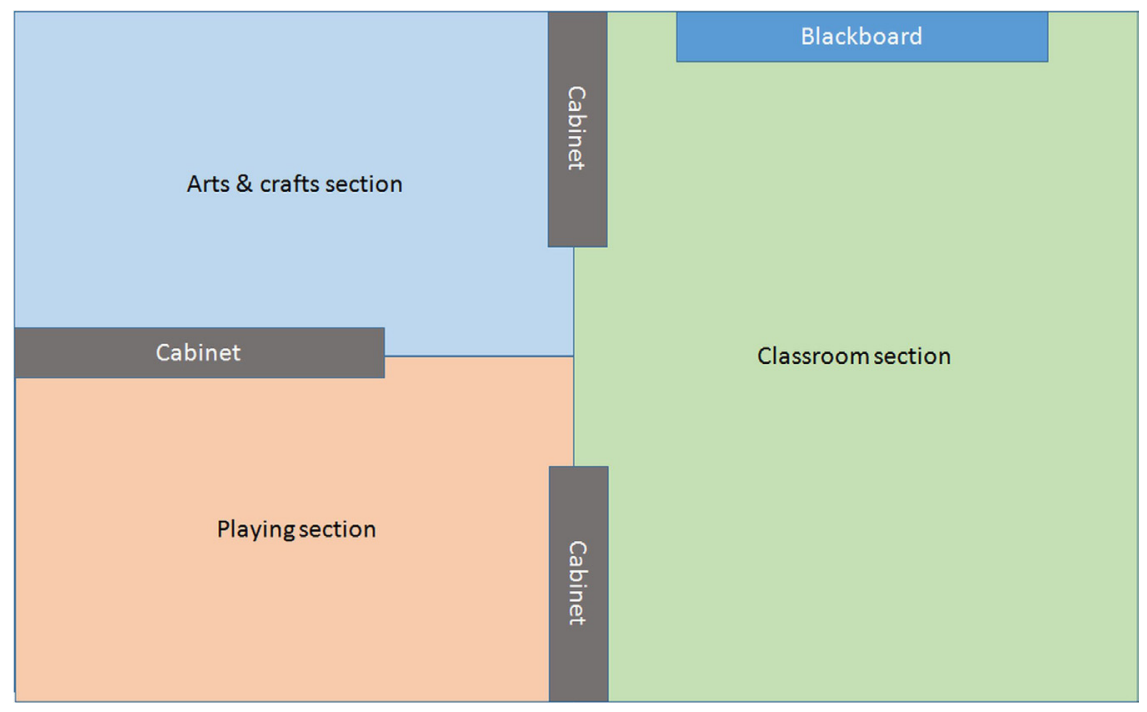

FIGURE 13. Remedial education room layout. Courtesy of the author.

Such instructions were often paired with the disposition of space: certain activities were associated with particular spaces, so that children would move to different sections of the room to read, eat, play, or study. Often children had difficulty letting go of one activity to move onto the next, even when the time was up. They would linger in the reading section, unable to give up the book that they couldn't finish, or would be caught up in the ordeal of arranging their crayons in a particular order of color long after the drawing time was over. In such cases, a staff member would stay with the child and remind him or her that the rest of the group had moved on to a different activity in a different part of the room. This seemed to be effective, because the child often glanced across the room to where everybody else was, and recognized that he or she was behind by that spatial distance from where he or she had been left alone. In some cases, the staff members pointed at the agenda on the board or to the clock, helping the child recognize that the time was over. When even that failed, they would tell the child that they would count to thirty and encourage him or her to finish up with the activity within that time frame so as to join everyone else. Activities were compartmentalized in this way through spatial and temporal allocation, and a great amount of emphasis was placed on the children's ability to perceive the rules of this structure and to regulate their behavior according to the collective schedule.

As an additional measure to enforce this rule, the staff members gave out stickers at the end of each activity; one sticker after the reading period, another after snack time, and another after the art activity. The children were told that they had to "be good" during the activities to earn these stickers, and the staff members 
often explained the rationale by which they had earned the stickers: "Thank you, Sakura, for being so quiet while I was giving out instructions. This is for you." "Yūichi, you did a great job in helping your friends. Here's your sticker." The distribution of stickers was part of the routine and seldom did any child fail to earn one. Even when a child threw a tantrum in the middle of an activity and had to be taken out to a different room to "cool down," he or she would be given the sticker upon returning: "Do you feel alright now? Can you promise that next time you'll talk to the teacher rather than screaming like that? Okay, here's yours then."

It seemed that the distribution of stickers was more about demarcating the end of a certain activity and helping the children move on to the next event in the day, rather than about rewarding praiseworthy behavior. The practice is comparable to the school setting, where children with developmental disabilities often encounter similar kinds of trouble moving from one activity to another, and where the bell is the primary cue defining the boundary between class, recess, and lunch. On the other hand, the time/space organization within the remedial education setting clearly enforced a certain mode of governmentality. It undoubtedly disciplined the children to follow the existing school system regimen, but it apparently left little room for the children to explore their interests, creatively engage with the activities, or to freely interact with others without the constraints of time and space (for a contrast with wartime Japan, see chapter 8).

The use of picture cards represented another salient feature of the kind of communication that took place between the staff members and the children. Not only were the day's activities depicted on large cards with colored pictures of toys (indicating play time), snacks, and books (for study time), but smaller picture cards were also used in various circumstances during the session. On one occasion, when one of the children displayed unwillingness to participate in an activity, a staff member walked up to him and showed him several cards, asking what he would like to do. He glanced through the cards and, without a word, slapped on one displaying the picture of a toy car. Seeing his response, the staff member said, "Okay, you want to play with cars. Good. The cars are in that basket. Let's go and fetch them." Holding his hand, the staff member led the boy to where the toy cars were stored.

Unlike the aforementioned girl with selective muteness, this boy was capable of expressing his opinion through words, but I learned that an open-ended question like "What do you want to do?" is often more difficult to answer for children with developmental disabilities; communication is made easier by offering them clear choices. This method worked particularly well with children who are stronger in visual input than auditory input, for they often seem to have difficulty taking in a full set of options when choices are spoken or read to them.

The physical layout of the room, visualized schedules, and clear task organization are all adopted from the Treatment and Education of Autistic and related Communication Handicapped Children (TEACCH) program. TEACCH was originally 
developed in 1966 by Eric Schopler, scholar and psychologist in the department of psychiatry at the University of North Carolina (UNC), as a statewide program for the treatment of autistic children in North Carolina. Sasaki Masami, a Japanese child psychiatrist and a close friend of Schopler's, made numerous visits to UNC and, from the early 1980s, was instrumental in bringing the ideas and practices of TEACCH to Japan. Today, components of TEACCH's treatment style are invariably incorporated into almost all remedial education programs, although few programs make the claim that their practices are strictly and exclusively aligned with TEACCH. In some ways, the essence of TEACCH, called "structured teaching," has become common knowledge among the professionals in the remedial education industry, wherein the "best practices" of remedial education often refer directly to Schopler's innovations: effective room layouts, schedule visualization and use of picture cards.

\section{SOCIAL SKILLS TRAINING AND STRATEGIES}

\section{OF SELF-CARE}

One day, the staff members for the remedial education program that I was observing decided to have the children interview one another. While the children got into pairs and started talking about their favorite TV programs and sports, a boy wandered off to a different section of the room and began playing with toys. A staff member walked up to him and spoke to him in a soft tone. "This isn't the time to be playing. What's wrong?" The boy glanced back at the staff member but didn't answer. "If you don't want to do the interview, you need to talk to Yamada-sensei" (Yamada was in charge of the interviewing activity). With this, the staff member held out his arm, encouraging the boy to stand up and go to Yamada-sensei. The boy hesitantly stood up and went to Yamada-sensei who was watching this interaction. He spoke slowly: "I don't want to do the interview." "Why not?" "It's not fun." After a moment of silence, Yamada-sensei said, "Alright then. Thank you for telling me. You have permission to sit at the back of the room and watch, but don't play with the toys because everyone else would want to do the same, and it won't be fair if only you are allowed to play." The boy nodded with a relieved look and walked to the back of the room, where the staff member who first approached him had pulled out a chair for him to sit on. He spent the next five minutes watching the rest of the class, but became increasingly restless. He finally decided to return to the group and was warmly welcomed by Yamada-sensei.

At the meeting held later in the day, I asked what the staff members thought about this incident. Yamada-sensei replied: "Of course there are times when kids don't feel like participating. We make it a point that that's alright, so long as they speak to one of the staff members about it. We're not forcing them to do anything. But it's problematic when they just wander off like he did; it's not acceptable behavior in school or at work. You need to be able to talk about it. I'm glad you brought 
this up, because it took us much time and effort to make the kids understand that rule." Another staff member added: "He said the interviewing wasn't fun, and that's okay for preschool kids, but if he were a bit older we wouldn't have tolerated that. Things you do in school aren't always fun, and that's not reason enough to leave the group. Kids in our older-aged group can be exempt from an activity only if they're not feeling well, or something."

Hearing this explanation, I realized that this was a form of social skills training. Social skills training (SST) constitutes a major part of intervention practices in the remedial education setting. In fact, SST has become prevalent in various programs for individuals with developmental disabilities; it is practiced in self-help groups for adults with developmental disabilities, and there are various training courses in which schoolteachers and parents learn the basics of SST. Robert Paul Liberman, a psychiatry professor at UCLA, originally developed the SST training concept in the 1970 and 1980 s as a rehabilitation program for persons with schizophrenia. His original work, however, is seldom referenced in the Japanese context. Instead, the term is used in a more generic sense to refer to a diverse range of activities and exercises aimed at enhancing children's capabilities to relate to others in socially appropriate ways. In this instance, the emphasis was not so much on making the children follow the strictly defined routine of the program as it was on helping them understand what constituted acceptable and inacceptable behavior within the context of a given circumstance.

Sometimes, social skills training was taken up in more explicit ways through activities such as role-playing. The roles were typically set up to simulate a situation where there was a clash of interests; sessions led to discussions about the appropriate course of action was to resolve the conflict. For younger children, the general purpose was to teach when to thank or apologize to others, and how to ask for favors. For older children, the scenario was often more realistic and thus complex, involving issues such as bullying, taking sides, reciprocating friendly approaches, and being sensitive to the age or social rank of others. Apart from this structured training, the staff members also gave frequent feedback on the way children spoke to one another and to the teacher. During a drawing activity, one boy asked for an extra piece of paper. Turning to a nearby staff member, he murmured, "paper," at which she handed him the paper replying, "It would've been better if you'd said, 'Please give me a piece of paper." In another instance, one child tripped over some Lego blocks with which another child was playing. The boy immediately apologized, "Sorry for stepping on them!" Seeing this, a staff member instantly gave him positive feedback: "That was a good way of apologizing. Well done!" It was through the accumulation of these consistent micro-level interventions that the children slowly learned the "correct" way to interact with others.

Acquisition of such social skills is considered an important component of remedial education programs, for it helps the children to get along better with their peers in school and other social occasions. Expressions of appreciation and 
apology do not come naturally for many children enrolled in remedial education programs. Instructions such as "try to walk in other people's shoes" and "you should reciprocate kindness" often don't register with them, especially with those with autistic tendencies. It was therefore important for children to have these typically unspoken rules of social interaction be overtly stated through specialized instruction. The staff members often joked about how children new to participating in the program would, without intending to hurt anyone, make mildly offensive comments about staff or the other children. One staff member reported, with a laugh: "When we first met, the first thing he said was 'You're too fat.' He was just being honest, you know. These kids are really honest/innocent (sunao) and have beautiful hearts." Not only the staff members of remedial education programs, but also many professionals and parents seem to think highly of the children's honesty. The distinction between honne (private self) and tatemae (the persona/mask) is learned early on in preschools and elementary schools; these principles constitute a critical dimension to Japanese socialization. The difficulty that the children with developmental disabilities experience in understanding and making use of this distinction in conversation is precisely what necessitates intervention in this field, but many adults, at the same time, seem to think of such honesty as an expression of "beautiful hearts," untainted by social imperatives. As one staff member confided, such honestly is representative of a candidness that fully socialized members of the society are deprived of: "We all think like that, you know, when you try to remember someone, you think, 'Oh that bald man' or 'That short woman' but you can't say that out loud, right?"

Social skills training is, therefore, a form of intervention in the broad sense of the term. But, more precisely, it is a means of having the children acquire the skills to cope in a society filled with people who interact and socialize in ways that may seem unintelligible to them. Without entailing a fundamental transformation in their worldview or personhood, SST helps them effectively "translate" between cultures, so to speak, through the acquisition of a particular mode of language. In this sense, SST is a technique of self-care; it is a survival skill that helps the children avoid unnecessary conflicts or tensions with others.

\section{CARING FOR THE CARETAKERS: MOTHERS AS RECIPIENTS OF SUPPORT}

While remedial education programs are principally designed according to the needs of children with developmental disabilities, they also serve an important function for the children's mothers. The brief visits when mothers come to drop off and pick up their children often entail chats with staff members, and casual reporting often takes place regarding how their children had been doing over the past week. The conversation naturally flows to the mothers' complaints about interactions with other family members or with the child's primary school administrators. 
More than once I saw mothers shedding tears while confiding their emotional burden and the sense of helplessness and solitude they sometimes felt in raising their children. Such conversations were semi-private. With voices kept low; the content of the discussions rarely entered the weekly staff meeting. Instead I often eavesdropped on such conversations while helping the children get ready to go home. "My mother-in-law disapproves of his disability and says he's just being lazy and keeps asking herself how he ended up this way. She's talking to herself but she knows I'm listening, so it's sort of directed at me, you know ..." "Yes, it's hard for people of that generation to understand." "Yeah I know, but ..." "Okāsan (mother), you're his only mother. I know it's hard, but you've got to hang in there (shikkari shinakya)."

The staff members listened, encouraged, supported, and sympathized with the mothers. It was clear that many of these mothers had few other places to share their feelings. Other than remedial education, there is in fact a dearth of communities and resources directed specifically toward parents who need emotional help in raising children with disabilities. Although parents' organizations fulfill this function in some ways, these are usually run by parents of relatively older children, given the amount of time and commitment that they require. Parents' organizations are also more inclined towards political advocacy and public awareness campaigns, rather than toward peer support around issues of day-to-day care. Mothers with younger children, therefore, have limited opportunities to interact with understanding professionals and sympathetic peers.

Raising a child with developmental disabilities is different from raising a child with congenital physical or intellectual disabilities. Because a developmental disability is usually not visibly identifiable, the child's behavior and inability to comply with certain rules or directions tend to be mistaken for a sign of irresponsible child-rearing practice and lack of discipline by the parents. Mothers involved in the parents' organizations often share bitter episodes of being wrongfully accused of some kind of complicity in their child's (mis)behavior. This social stigma is historically rooted in a long genealogy of scholarship, as well as popular representation that has been instrumental in producing and perpetuating the parentblaming (and especially mother-blaming) discourse. The "refrigerator mother" theory (Bettelheim 1967) blamed mothers as the primary cause for their children's autism, and in the book's Japanese counterpart, the notion of "illness caused by the mother" (Kyūtoku 1979), was used to critique industrialization as having "negatively" shifted the lifestyle of Japanese women, the argument being that modern women had become "narcissistic" and thus were lacking in the "child-rearing instinct” (Lock 1987).

Although these ideas are rarely voiced in such explicit ways today, mothers raising children with developmental disabilities continue to be the target of suspicion and criticism. As exemplified in the conversation cited above, mothers also find themselves in difficult positions within the extended family. The responses of 
in-laws (the father's parents) usually manifest as either mother-blaming or plain indifference. Family members all too often blame the mother for the child's condition, directly or indirectly, hinting at her inadequacy as the primary caretaker. Mothers tend to internalize this accusation to varying degrees, which consequently shakes their confidence in their own child-rearing skill. In the second type of response, that of the extended family's indifference, inlaws might mention that their children (the husband and/or his siblings) had tendencies similar to developmental disabilities when growing up, suggesting that the mother is being too sensitive, overreacting to behavior that is "normal." In such cases, mothers often have to fight against the family's passive resistance in order to enroll their children in remedial education programs and to get other professional help. ${ }^{1}$ In either case, what further complicates family relationships is the idea of blood and heritability.

Research shows that developmental disability is to some degree genetically inherited, although it cannot be traced to a single gene and its mechanism of inheritance is as yet unclear (Bailey et al. 1995; Castles et al. 1999). Most mothers are aware of this, having gained the information through self-help books or other media. Members of the extended family, on the other hand, seem to be mostly unaware of up-to-date information, and thus their responses rely on popular beliefs and uninformed assumptions. In spite of, or precisely owing to this knowledge gap, mothers tend to take their in-laws' comments to heart, interpreting them in light of ubiquitous misinformation and confirming their legitimacy. In the typical parent-blaming scenario, the mother is blamed for introducing a problem that had not existed in the husband's family lineage. One mother I interviewed said that her mother-in-law explicitly stated, "It's not on our side, so it must be in yours. You know someone in your family like this, don't you?" Sometimes the mother herself identifies with the child, recalling that she had similar experiences during childhood, which often deepens and exacerbates her sense of inadequacy. In the typical scenario of extended family indifference, it is very often the case that the father of the child, and/or his siblings, had similar issues, triggering the suspicion of the in-laws that the mother is making a "big deal" out of the child's uniqueness. In this case, the mothers believe that there is indeed a genetic component to the child's condition and that it just went unnoticed for the earlier generations, which only reinforces the mother's urge to seek support and intervention for the child despite the lack of cooperation from her extended family members.

It is under such circumstances that mothers come to rely on remedial education staff members as supportive mentors. Remedial education staff members are not psychiatrists (if they were, they might, in fact, appear too professional-too distant-to the mothers), nor are they schoolteachers or officers in the public welfare administration (who might be threatening in another sense, as stakeholders with authority to provide or withhold resources for children). Instead, remedial education staff members are both accessible individuals with specialized knowledge and providers of the service that the parents have purchased. The relationship 
they provide aims to strike a balance between the personal and the professional. There is also a gender component to this relationship: a majority of the remedial education staff members are women in their late-twenties to forties, meaning that they are usually around the same age or slightly older than the mothers, making them reassuringly approachable.

Staff members know that the mothers' understanding of, and commitment to, remedial education practice-including its application at home-counts a lot towards a fruitful intervention. Given the limited time that the children spend in remedial education programs (typically around two to three hours a week), the staff members try to engage the mothers as much as possible. Such engagement also entails that the staff members be the mothers' best listeners, at times providing a shoulder to cry on. Thus remedial education programs become a place where mothers can confide their stories and release their stress and pressure, providing a short respite from their daily lives. The staff members then encourage them and help them to move forward.

\section{AMBIVALENCE TOWARDS THE NOTION OF "CURING":} REMEDIAL EDUCATION AS A LIMINAL SPACE

As I have discussed, remedial education involves the practice of caring in multiple dimensions. The other key component of remedial education that this chapter seeks to engage, the idea of curing developmental disabilities, is similarly complex. When defined as the complete elimination of symptoms, the concept of "cure" becomes a controversial issue among professionals in this field. Throughout my fieldwork, I was taught by the staff members-both explicitly and implicitly-that cure is not the goal of their program, and that it is quite inappropriate to question remedial education's efficacy in those terms. Indeed, there is a consensus within the medical community that developmental disabilities cannot be cured completely through intervention. Still, the sensitivity displayed by remedial education administrators towards the idea of curing went beyond a simple embrace of this notion, which triggered my interest in exploring this issue further. While distancing themselves from the idea of cure, the administrators usually designed their programs to help children expand the realm of their achievement in order to facilitate a positive change in their developmental trajectory. In that sense, it can be said that remedial education staff were negotiating a blurred line between care and cure in invoking an image of the optimum child as the goal of their programs while carefully distancing themselves from the idea of blindly molding the child to fit the social norm.

Part of this negotiation has to do with remedial education's close relationship with mothers. As I have pointed out, there is an long genealogy of literature of mother blaming and, not surprisingly, such discourses persist. Sankei News, a newspaper with nationwide circulation, did a series in 2010 on parental education 
(“Oyagaku Q\&A” 2010). The series emphasized the importance of the parents' roles in supporting the healthy development of children, stating that developmental disabilities can be prevented if parents reclaim "traditional" Japanese childrearing ways. This article stirred a great deal of controversy within the online community of parents, not only because the claim was unsubstantiated, but also because it reads as a shameless revisiting of the idea that illness is caused by the mother. In this discursive context, the notion of curing developmental disabilities becomes a highly sensitive issue, for it evokes the supposition that it is somehow possible to undo the disability through appropriate training and discipline. This idea, then, alludes to the problematic and stigmatizing conclusion that the disability in fact results from certain parenting dynamics.

This is obviously not the only story. The informed ambivalence that the remedial education staff holds towards the notion of cure has much to do with the idea of liminality associated with the space of the program. In a way, both staff members and mothers consider the remedial education program to be an experimental space where children are trained to acquire basic social skills through trial and error. Failing to comply with social norms and expectations is not seen as a problem, so long as nonconforming behaviors are contained within the space of the program, because, in that context, they do not result in significant practical consequences such as having strained relationships with friends or being reprimanded by schoolteachers. For that reason, a staff member will gently tell the child what is wrong and lead him or her to make corrections, so that new behaviors can be practiced in real-life settings. In this sense, remedial education constitutes a liminal space, one free from the social imperatives of actual society. It is a kind of rehearsal-a "mock" society that simulates real-world events. At the same time, though, I found that many staff members shared a romanticized idea of remedial education space as being a space for metamorphosis, where children come to self-awareness and reach significant developmental milestones through their support. Staff members took meticulous notes on children's behaviors and reactions, while awaiting transformative moments with hope. Accounts of best practices, as reported in publications and conferences, are filled with glorious stories of children going through visibly identifiable changes and positive transformations in social engagement. In this sense, the space of remedial education functions as a buffer zone; the programs help bridge the gap between the personal and the social realm, home and school, and relative immaturity and age-appropriate development.

This unique characteristic is at the heart of many remedial education practices. As I have discussed, the process of trial and error is considered to be an integral part of the learning experience. The staff members quietly observe as the child makes mistakes, postponing intervention while the child finds his way on his or her own, and praising his accomplishments when he or she does so. This kind of practice, the staff explains, provides an education that cannot take place in schools with large class sizes and standardized, impersonal curricula. The rules are generally 
looser than those in the public schools. Staff members have room to provide and engage in alternative modes of communication, such as encouraging the girl with selective muteness to take part in roll call by slapping the hand of a staff member.

Rather than focusing solely on the children's adaptability to the existing educational system, remedial education programs place particular importance on fostering a space where children can experiment and learn in a less structured way, express themselves uniquely, and interact with others more freely. In this sense, although they prepare children for school, remedial education programs do not see themselves as an extension of the public school system, nor do they emphasize the need to mold the children's behavior to adapt to the regular classrooms. In fact, many staff and administrators that I met during the course of my fieldwork seemed to believe that adaptation to school is merely one of the short-term goals, and that remedial education should be conducted with a vision of life beyond school, so as to help the children grow up to be independent members of society, with fulfilling jobs and rich social lives. This promise was reflected in conversations during staff meetings; the staff members very rarely, if ever, spoke from a paternalistic position. They did not see themselves as representative of an institution to which a child should adapt. Rather, they tried their best to put themselves in the children's shoes and to understand how children see and experience the world.

The way in which remedial education grapples with developmental disabilities as a category of disability can be understood as a form of resistance to ableist ideology. Ableism views disability as a deviance from normalcy and thus establishes an imperative to train children to "overcome" their difference and behave as "normally" as possible (Linton 1998). In other words, although remedial education aims to scaffold the children's development, it does not embrace the corrective undertone of authoritatively disciplining the children to forcefully fit them into the mainstream society. Being a "buffer zone" or a space of in-betweenness, it is one of the few places for the children to engage in learning experiences at their own pace, to comfortably be who they are without having to worry about their deviation from the idealized norm. Remedial education staff members are well aware that the ideology of "curing" developmental disabilities would entail a more paternalistic, top-down approach that identifies pathology in the children's behavior and frames difference as a problem to be resolved. In that sense, they reject the premise that children are "afflicted" with a disability that necessarily bars them from mainstream society until they are appropriately treated and trained to conform to the norm. To be sure, the general public's understanding of remedial education is often not too far from the pathologizing model that remedial education staff seek to avoid, but those who work in the industry would see such an agenda as denying the heart of their practice. As much as it is an institutionalized program that tailors to and maintain links to external resources such as clinics, hospitals, schools, and welfare offices, it is also one of the few places where children and their mothers can feel safe and accepted without being pushed and shoved to "fit in." 


\section{CULTURAL NOTIONS OF EMBODYING ILLNESS/}

DISABILITY

At the end of each day's program, there was a staff meeting to go over the day's activities. On one particular day, the seven staff members who were present sat around a small table in the meeting room and opened their notebooks to take notes. One of the senior members took the initiative and began by going over the operation of the activities: "Some of the children didn't understand the instructions in the role-playing activity and were confused during the first round. Next time we should have a visual board to explain the roles." Others added comments: "Perhaps it would be a good idea to have several staff members come up to the front and play it out, wearing paper masks for each character." "I think the confusion was caused by giving actual names to the characters. We should've just named them 'student A,' 'student B,' 'teacher', and so on.' All members actively participated in the discussion, nodding at one another's suggestions and taking notes. They often referred to ideas and practices they had heard from colleagues in other remedial education institutions that had demonstrated positive outcomes, or cited journal articles and conference presentations that they recently read or attended. In fact, remedial education for children with developmental disabilities has grown into a large industry; major bookstores invariably have sections devoted to remedial education practices, and there are conferences, journals, and funding sources available for professionals. This has entailed the professionalization of remedial education workers and enabled the creation of a forum where knowledge gained from practice is accumulated, evaluated, and disseminated as standardized practice to other remedial education settings across the nation.

The meeting continued, and the discussion began to turn attention to individual children. Each staff member reported on the child in her charge. Many of the comments made in this part of the meeting anticipated how each child was experiencing the environment around him or her: "I think the noise coming from the air conditioner was so overwhelming that he couldn't make out my voice." "He was having a hard time folding the origami, and he finally panicked because he couldn't tolerate his own clumsiness." "I didn't look closely enough, but perhaps she was doing it according to a pattern" are a few of the comments that I heard being made at these meetings, each alluding to how a particular child experienced the day's activities in ways that might be different from others, and thus not immediately apparent to the observer. Their narratives were based on the shared understanding that children with developmental disabilities experience the environment in a different way, and that the disability is manifested precisely in their unique cognition. ${ }^{2}$ In essence, developmental disability is seen as deeply embedded in and inseparable from the individual's embodied experience, in a way that is perhaps close to a chronic or constantly present illness or innate weaknesses of the constitution as described by Ohnuki-Tierney (1984). She writes: "Written in 
two characters, the first one meaning 'carrying' and the second one 'illness', jibyō means an illness that a person carries throughout life, and suffers at some times more acutely than at others. People very often attribute their 'down' condition to an attack by jibyö" (Ohnuki-Tierney 1984: 53).

Ohnuki-Tierney cites rheumatism, weak stomach, and high blood pressure among her examples of chronic illness. Innate constitutional weakness, on the other hand, is defined as inherent to the constitution with which one is born, which might be healthy, weak, or susceptible to certain illnesses, and as Ohnuki-Tierney points out, chronic illness and constitutional weakness are at times interchangeable. Although developmental disability is not listed in the repertoire of either, it could just as well be considered as either or both, in the sense that it is something that one is born with and that one has to deal with throughout life; it is inseparable from the character of the person and is also an embodied trait, which manifests itself strongly in some instances while at other times remains latent. The staff meeting can be understood as an exchange of information and ideas regarding the management of a chronic condition, over which the child himself or herself still has little control.

Ohnuki-Tierney goes on to argue that, although Japanese culture provides various means to deal with chronic illnesses, they are "aimed not at the elimination of pathogens, as in biomedicine, but at the restoration of the balance between opposing forces in the body" (Ohnuki-Tierney 1984: 73). In other words, it is essential to learn to live with a chronic condition, effectively managing it to circumvent difficult situations. The idea of "curing" developmental disabilities, on the other hand, evokes the premise of eliminating a foreign pathogen that is inhibiting the child's true individuality. The remedial education programs, in seeking to help children to embody their disability, can be seen as a practice guided by insights echoing those informing Ohnuki-Tierney's work. Remedial education staff guide children with developmental disabilities toward coping with disability in a way that fulfills their academic and social responsibilities while allowing them to feeling comfortable in the expression of their own uniqueness.

\section{CONCLUSION}

What I have attempted thus far is to organize my ethnographic data and lay out my thoughts in light of the key concepts of care and cure. The actual activities, interactions, and exchanges that take place in the programs are more complex than I have described here. The care/cure axes are experimental theoretical devices that I utilize to distill and reframe the essence of remedial education practice. My informants never explicitly referred to the dichotomy of care and cure, nor did they categorize or identify their jobs in these terms. They did, however, have a specific understanding of what intervention should and should not entail, one that seemed to be founded upon a particular understanding of developmental disability and the children who struggle with it. By theorizing this interpretive framework, I am 
attempting to capture and illuminate some dimensions of the culture of remedial education that are not always apparent, even to those in closely related fields such as education and child psychiatry.

On the other hand, how children are experiencing these programs, what they actually learn, and how they would reflect on their experience later in their lives remains a field to be explored in the future. During my fieldwork, I overheard conversations about how a child who was excelling in the program was experiencing difficulty in real-life social interaction involving stickier situations. I never asked to interview or observe the children outside the program, but wondered how they, in fact, applied what they learned, and whether and how it actually helped them get by. Remedial education is, for better or for worse, a safe laboratory, one that does not replicate the world outside. As a means to move beyond this limitation and to envision a kind of intervention that unfailingly prepares children for the world outside, perhaps there needs to be a stronger focus on peer interaction and on "self-learning" as a practice apart from the adult-initiated learning model that remedial education still tends to privilege. Throughout my fieldwork, I heard the word kakawari used numerous times by those in the remedial education industry. While the word literally means involvement or commitment in a relationship, staff members of programs used the term to refer to the ways in which they engage with the children; in that context, the term is defined and shaped through their understanding of the ideal style of intervention. "We need to change our way of involvement with him, because he's not responding well," was a comment that I heard often in meetings. However, at the same time, kakawari is a word that refers to interpersonal relationships in a very general sense. To ask about one's kakawari with another person is to inquire into how one met that person, what the two have in common, and what ties them together. The image behind this lay usage of the term is that of two equal individuals involved in a mutual relationship. The conflated interpretation of kakawari therefore brings intervention and relationship together, indicating that the practice of remedial education, when stripped of its techniques and methods, can be distilled into personal relationships among the individuals present, be they staff members or children. It is a practice of engaging with the children while enhancing their ability to engage with others. In this sense, remedial education should be open to multitudinous and diverse forms of interaction, not limited to the one-directional endowment of knowledge and care from the giver to the receiver. The increasing awareness about developmental disabilities among the general public may entail the involvement of other experts from unexpected fields and industries in the near future, opening up new and different possibilities of intervention.

\section{NOTES}

1. In either case, the presence of the child's father is minimal. In some of the interviews with mothers, I explicitly asked what their husbands were doing about the situation, but was unable to elicit much 
information. A typical response was that the father was busy with work, had agreed to send the child to remedial education when his wife brought it up, but there hadn't been any further discussion of the topic. Only once did I see a father pick up his child from remedial education, but he left quickly without talking to the staff members.

2. Adults with developmental disabilities have written about their unique bodily experiences. For example, see Ayaya and Kumagaya 2008.

\section{BIBLIOGRAPHY}

Note: Unless noted otherwise the place of publication for Japanese books is Tokyo.

Ayaya Satsuki and Shinichirō Kumagaya. 2008. Hattatsu shōgai tōjisha kenkyū [Personal research on developmental disability]. Igakushoin.

Bailey, Anthony, et al. 1995. "Autism as a Strongly Genetic Disorder: Evidence from a British Twin Study." Psychological Medicine 25(1): 63-77.

Bettelheim, Bruno. 1967. The Empty Fortress: Infantile Autism and the Birth of the Self. New York: The Free Press.

Castles, Anne, et al. 1999. "Varieties of Developmental Reading Disorder: Genetic and Environmental Influences." Journal of Experimental Child Psychology 72(2): 73-94.

Itō, Ryuji. 1970. "Seishin hakujakuji no chiryō kyōiku (2) Shinrigakuteki tachiba kara" [Treatment education of children with mental deficiency (2): From a psychological perspective]. Journal of the Japanese Association for the Scientific Study of Mental Deficiency 4, no. 2.

Kan, Osamu. 1969. "Seishin hakujakuji no chiryô kyôiku" [Treatment education of children with mental deficiency]. In Seishin hakujaku no igaku, edited by Kishimoto Ken'ichi. Kanehara.

Kyūtoku, Shigemori. 1979. Bogenbyō [Illnesses caused by mothers]. Kyōiku Kenkyūsha.

Linton, Simi. 1998. Claiming Disability: Knowledge and Identity. New York: New York University Press.

Lock, Margaret. 1987. "Protests of a Good Wife and Wise Mother: The Medicalization of Distress in Japan." In Illness and Medical Care in Japan, edited by Edward Norbeck and Margaret Lock, 130-57. Honolulu: University of Hawaii Press.

Ohnuki-Tierney, Emiko. 1984. Illness and Culture in Contemporary Japan: An Anthropological View. Cambridge: Cambridge University Press.

“Oyagaku Q\&A.” 2010. Sankei News. Series published January to June. http://sankei.jp.msn. com/life/education/. 